\title{
Correlations between South African Red Grape and Wine Colour and Phenolic Composition: Comparing the Glories, Iland and Bovine Serum Albumin Tannin Precipitation Methods
}

\author{
W.J. du Toit*, M. Visagie \\ Department of Viticulture and Oenology, Private Bag X1, 7620 Matieland (Stellenbosch), South Africa
}

Submitted for publication: August 2011

Accepted for publication: September 2011

Key words: Phenolic extraction, Glories, Iland BSA methods, anthocyanins, tannins

\begin{abstract}
Phenolic compounds in red grapes might give an indication of phenolic and colour compositions of the resulting wine. This work compared the Glories, Iland and Bovine Serum Albumin (BSA) tannin precipitation methods for phenolic characterization of South African Pinotage, Merlot, Shiraz and Cabernet Sauvignon red grape samples $(n=31)$. Significant positive correlations were found for certain phenolic characteristics in the grapes measured by these methods. Levels of phenolic compounds in the grapes and correlating wines were in line with literature. Merlot samples often associated more with higher concentrations of seed tannins, which were also reflected in the wines. Significant correlations were also found with the colour characteristics of the resulting wines and some anthocyanin related measurements in the grapes with the Glories and Iland methods, with the latter correlating slightly better. Significant positive correlations were also found between grape and wine tannins as measured with the BSA method. However, malolactic fermentation changed some of these correlations and this needs to be investigated further. This work might give wine producers as well as wine analyses laboratories valuable information regarding the suitability of these methods to characterize the phenolic composition of South African red grapes and their resulting wines.
\end{abstract}

\section{INTRODUCTION}

Phenolic compounds originating from grapes, especially condensed tannins and anthocyanins, play a critical role in the colour, astringency, mouth feel and general quality of red wines (Rossouw \& Marais, 2004; Du Toit et al., 2006b). Anthocyanins are primarily responsible for the colour of young red wines and are found in the vacuoles of grape skin cells, while tannins are mostly present in the grape skins and seeds. During maceration and fermentation, anthocyanins and condensed tannins are extracted, leading to an increase in the anthocyanin content, colour density and tannin concentration and total phenolics of red wines (RomeroCascales et al., 2005; Ribéreau-Gayon et al., 2006; Jensen et al., 2008). Anthocyanin and condensed tannin concentrations in grapes depend on many factors, such as cultivar, terrior, viticulture practices and ripening stage. It is thus important for the wine producer to be able to assess the anthocyanin, condensed tannin and total phenol concentrations in grapes and have an idea how they would reflect in the corresponding wine (De Freitas et al., 2000; Gonzalez-Neves et al., 2004; Celotti \& Carcereri De Prati, 2005; De Beer et al., 2006; Fournand et al., 2006; Downey et al., 2007; Cagnasso et al., 2008; Jensen et al., 2008).
In a winery, relatively rapid, inexpensive and easy to perform methods are thus required to assess colour, tannin and the total penolic composition of red grapes at harvest time, as many of them do not have access to more advanced phenolic analyses techniques such as HPLC. The bovine serum albumine precipitation (BSA method, Harbertson et al., 2008) spectrophotometrically measures the condensed tannin concentration of both grape must and wine which are precipitated by BSA. Two of the most commonly used spectrophotometrical methods used in South Africa for phenolic characterization of grapes are the Iland method, developed in Australia (Iland, 2004) and the Glories method (Ribéreau-Gayon et al., 2006), developed in France. The Iland method measures total phenols and anthocyanins in acidified grape pulp to which $50 \%$ alcohol has been added. The Glories method is traditionally used to measure extractable anthocyanins and total anthocyanins at $\mathrm{pH} 3.2$ and $\mathrm{pH} 1$ respectively, without the addition of alcohol. This allows the determination of the degree of anthocyanin extractability, which gives an indication when anthocyanin are not only at their maximum levels in red grapes, but also optimally extractable during vinification (Ribéreau-Gayon et 
al., 2006). The Glories method also measures seed tannins, skin tannins and total phenolics in red grapes. In South Africa, $\mathrm{pH}$ levels are often higher than those encountered in European musts, raising the question whether the extractable anthocyanin as determined with the Glories method should not be performed at a higher $\mathrm{pH}$.

Fragoso et al. (2010) compared three extraction techniques to assess the anthocyanin and phenolic composition of red grapes, but did not investigate how they would correspond with their wines. A few other studies have looked at the phenolic composition of grapes and how they are reflected in the corresponding wines, but most of these analyses have been done on wines just after alcoholic fermentation (Marais \& October, 2005; Cagnasso et al., 2008; Jensen et al., 2008) and it is well known that the phenolic and colour composition of red wines can change during malolactic fermentation (Guadalupe and \& Ayestaran, 2008; Geldenhuys, 2009). Little data has been published on this field, especially under South African conditions. The main aim of this study was to assess the anthocyanin, tannin and total phenolic composition of different South African red musts with the Glories, Iland and BSA methods and to compare how well these parameters correspond in the resulting wines after alcoholic and malolactic fermentation. An additional aim was to assess the effect of increasing the $\mathrm{pH}$ in the extractability index of anthocyanins with the Glories method.

\section{MATERIALS AND METHODS \\ Chemicals used}

Hydrochloric acid (1M, 32\% HCl, Merck), Sodium hydroxide (Merck), glacial acetic acid (Merck), sodium chloride (Saarchem), potassium tartrate (Sigma Aldrich), ethanol (Absolute Ethanol, Merck), triethanolamine (Sigma Aldrich), Sodium dodecyl sulphate (Sigma Aldrich), iron chloride (Radchem), sodium sulphate (Merck), bovine serum albumin (Sigma), catechin (Sigma), acetaldehyde (Merck), sodiummetabisulphide (Radchem), L(+) tartaric acid (Merck). All pH adjustments of the buffers for the BSA method were done using either $1 \mathrm{M}$ hydrochloric acid (Merck) or $1 \mathrm{M}$ sodium hydroxide (Merck).

\section{Grape samples used}

The four red cultivars most widely planted in South Africa, Pinotage $(n=8)$, Merlot $(n=10)$, Shiraz $(n=5)$ and Cabernet Sauvignon $(n=7)$, were used in this study during the 2010 vintage. Thirty one grape samples (20kg each) were received from different vineyards in the Stellenbosch, Robertson, Rawsonville, Durbanville, Somerset-West, Franschhoek and Hermanus districts of the Western Cape, South Africa. Grapes were picked at commercial harvest and were transported in plastic crates to the experimental cellar of the Department of Viticulture and Oenology, Stellenbosch University. Grapes were stored overnight at $4^{\circ} \mathrm{C}$ and 250 representative berries were collected the next morning from each crate for analysis. The vinification process was started on the same day.

\section{Winemaking}

Grapes were crushed, destemmend and $30 \mathrm{mg} / \mathrm{L} \mathrm{SO}_{2}$ from a $2.5 \% \mathrm{SO}_{2}$ solution was added to the must. The total soluble solids of each sample were determined with a Balling meter according to Iland (2004). The total acidity and $\mathrm{pH}$ were determined with the Metrohm titration unit (Metrohm Ltd., Switzerland). When the total acidity of the musts were not measuring $6.0 \mathrm{~g} / \mathrm{L}$, it was adjusted to this acidity using tartaric acid (Natural L (+) Tartaric acid, Bren-O-Kem (PTY) LTD, Wolseley, South Africa). After an hour the musts were inoculated with Saccharomyces cerevisiae strain NT116 at $0.3 \mathrm{~g} / \mathrm{L}$ according to the supplier's recommendations (Anchor Yeast Biotechnologies). The following day $0.5 \mathrm{~g} / \mathrm{L}$ diammoniumphosphate was added. Every day, the skins and juice were mixed three times by punching down to facilitate phenolic and colour extraction. All alcoholic fermentations were performed at a temperature of $23^{\circ} \mathrm{C}$ in $20 \mathrm{~L}$ food grade plastic buckets until the sugar concentrations reached $0{ }^{\circ} \mathrm{B}$. The skins were then separated from the wine and pressed in an open basket press to a pressure of 0.5 bar. The pressed wine and free run wine was then mixed in $4.5 \mathrm{~L}$ glass bottles with airlocks and inoculated with Viniflora Oenos (CHRHansen, Lake International Technologies, South Africa) starter cultures for malolactic fermentation (MLF) at $10^{6} \mathrm{cfu} /$ $\mathrm{mL}$ as prescribed by the supplier. Malic acid concentrations were monitored with a GrapeScan FT 120 instrument (Foss Electric, Denmark) (Nieuwoudt et al., 2004). This instrument utilises Fourier transform infrared spectroscopy (FT-IR). All samples were degassed by filtration before the analysis, using the Filtration Unit (type 70500, Foss Electric, Denmark) with filter paper circles graded at 20-25 $\mu \mathrm{m}$ and with a diameter of $185 \mathrm{~mm}$. MLF was considered completed when the malic acid concentrations reached $<0.3 \mathrm{~g} / \mathrm{L}$.

\section{Grape extraction procedures and grape and wine phenolic and colour analyses}

The repeatability of the Glories and Iland methods were tested by performing each analysis three times on the same 2010 Merlot and Shiraz grape samples. This was done in the same way as those performed on the 31 grape samples described in the following section.

Before destemming, 250 berries were representatively picked from each crate and mixed thoroughly in a plastic bag. One hundred berries were then taken from the bag and phenolic and colour characteristics determined according the Glories index (Ribéreau-Gayon et al., 2006). The remainder of the berry sample was frozen at $-20{ }^{\circ} \mathrm{C}$ for later analyses with the Iland and BSA methods. For the Glories method, the grape sample, including the skins and seeds, was homogenized for $4 \mathrm{~min}$ at $24000 \mathrm{rpm}$ (IKA T18 Ultra Terrax homogenizer) and two $25 \mathrm{~g}$ samples of the resulting paste added to solutions with a $\mathrm{pH}$ of 1 (using $0.1 \mathrm{M} \mathrm{HCl}$ ) and 3.2 (using $0.034 \mathrm{M}$ tartaric acid) respectively. The first is used to measure the total anthocyanins in a low $\mathrm{pH}$ medium, while the second is used to measure extractable anthocyanins under wine conditions. The samples were then extracted for $4 \mathrm{~h}$ at room temperature, filtered through glass wool and used in a Glories method analyses. The effect of changing the $\mathrm{pH}$ of extractable anthocyanins was also investigated and this analysis were performed at both 3.2 and 3.6.

The Glories method was adjusted slightly by calculating the extractability index of anthocyanins in the grapes (EAG) with the following formula: $\mathrm{EAG}=[1-(\mathrm{A} 1 \mathrm{G}-\mathrm{A} 3.2 \mathrm{G} / \mathrm{A} 1 \mathrm{G})]$. 
For the Iland and BSA methods, within 3 months of being frozen, the grapes were allowed to thaw and 50 berries homogenized in the same manner as described above. One gram of the paste was then added to each of a $50 \%$ ethanol solution (BSA method) and a $50 \%$ ethanol solution with pH 2 (adjusted with $\mathrm{HCl}$ ) (Iland method) and left for $1 \mathrm{~h}$ at room temperate. After an hour a supernatant was obtained by centrifuging the homogenate at $3500 \mathrm{rpm}$ for $5 \mathrm{~min}$. In the case of the BSA method this supernatant was used to determine the tannin levels in the grapes homogenate Habertson et al., (2008). The BSA method was performed in duplicate on each sample. In the case of the Iland method, $1 \mathrm{~mL}$ of this supernatant was then further diluted with 10 $\mathrm{mL} 1 \mathrm{M} \mathrm{HCl}$ and left at room temperature before the analysis were performed Iland (2004).

Fifty milliliters of wine was drawn after alcoholic fermentation (AF) and MLF and frozen at $-20{ }^{\circ} \mathrm{C}$ for later analyses. The wines were all analysed within 3 months of freezing. Samples were thawed and centrifuged at 2500 rpm for $1 \mathrm{~min}$ to remove solids. The supernatant was then used in a range of phenolic, colour and the BSA analyses. Different spectrophotometric analyses were conducted with a spectrophotometer according to Boulton (2001) and Iland et al. (2004). These included wine colour density, modified wine colour density (the modified version of the analysis negates the effect of $\mathrm{pH}$ and $\mathrm{SO}_{2}$ on the analysis), total red pigments, total phenolics, estimate of $\mathrm{SO}_{2}$ resistant pigments and co-pigmented anthocyanins. Total anthocyanin and tannins concentrations in the wines were determined according to Ribéreau-Gayon et al. (2006) and Habertson et al. (2008) respectively.

\section{Statistical analysis}

Intraclass correlations (ICC) were used to compare selected BSA repeats and the Glories determination at $\mathrm{pH} 3.2$ and 3.6. Comparisons of the 4 cultivars were done using oneway ANOVA and Fisher LSD post hoc tests. Principal Component Analysis (PCA) and PCA biplots were used to graphically display groupings of wines samples relative to the measurements made on them. Spearman correlations were used to test for relationships between different measurements.

\section{RESULTS AND DISCUSSION}

The different compounds which were analysed and their abbreviations are listed in Table 1 for both the grapes and wines.

\section{Repeatability of the methods}

The average, standard deviation and coefficient of variance values for three repeat analyses of Merlot and Shiraz samples were determined (results not shown). Coefficient of variance values were in most cases lower than $5 \%$ for the characteristics analyzed with these two methods, except for TPG which was $8 \%$. This indicates good repeatability with the Glories and Iland methods. The Interclass correlation (ICC) value for the BSA method performed on grapes was also established and found to be 0.97 for 9 randomly chosen samples, indicating the repeatability of the method.

\section{Effect of changing the $\mathbf{p H}$ in the Glories method}

The extractable anthocyanins in grapes $(\mathrm{A} 3.2 \mathrm{G})$ as determined with the Glories method was originally performed at $\mathrm{pH} 3.2$. It is well known that $\mathrm{pH}$ levels in red grapes from hotter countries may be higher, with $\mathrm{pH} 3.6$ at harvest not being uncommon. Romero-Cascales et al. (2005) changed the $\mathrm{pH}$ of this medium to 3.6 , which they claimed is better suited to musts originating from the Jumilla region in Spain, but they did not compare it the same medium at $\mathrm{pH}$ 3.2. This study investigated the effect of performing the Glories method (extractable anthocyanins) at both $\mathrm{pH} 3.2$ and 3.6. The ICC values of TPIG, EAG, A1G, A3.2G, SkTG, SeTG and $\mathrm{Mp} \% \mathrm{G}$ were $0.89,0.89,0.99,0.96,0.96,0.76$ and 0.83 , respectively. This indicates that the values obtained at either $\mathrm{pH} 3.2$ or 3.6 were very close and that increasing the $\mathrm{pH}$ to 3.6 did not play a significant role. The following reported data was only obtained at $\mathrm{pH} 3.2$.

TABLE 1

Analyses and abbreviations used in this study.

\begin{tabular}{lll}
\hline & Characteristic analysed & Abbreviation used in text \\
\hline Glories (grapes) & Total phenols & TPIG \\
& Extractability index of anthocyanins & EAG \\
& Total anthocyanins & A3.2G \\
& Extractable anthocyanins & SkTG \\
& Skin tannins & SeTG \\
& Seed tannins & Mp\%G \\
BSA tannin index (grapes) & Contribution of seeds to phenols & BSAg \\
Iland (grapes) & Tannins precipitated by BSA & AI \\
& Anthocyanins & TPI \\
Wines analyses* & Total phenols & TP \\
& Total phenols & TRP \\
& Total red pigments & CD \\
& Colour density & MCD \\
& Modified colour density & A \\
& Anthocyanins & CP \\
*a and b next to wine abbreviations in text indicates samples drawn after AF and MLF, respectively
\end{tabular}

\footnotetext{
* $\mathrm{a}$ and $\mathrm{b}$ next to wine abbreviations in text indicates samples drawn after AF and MLF, respectively
} 


\section{Colour and phenolic composition of grapes}

The average soluble solids, $\mathrm{pH}$ and total acidity of the grapes samples can be seen in Table 2. In terms of sugar level, only the Pinotage and Cabernet Sauvignon were significantly different from the other. In general, levels of phenolic compounds were in line with those found by other studies on red wine grapes (Gonzáles-Neves et al., 2004; RomeroCascales et al., 2005; Cagnasso et al., 2008; Jensen et al., 2008; Fragoso et al., 2010). One way ANOVA analysis on phenolic and anthocyanins on the grapes, did not yield significant differences between the cultivars, except for EAG, SeTG and Mp\%G. The extractability of anthocyanins was significantly higher in Cabernet Sauvignon grapes than in the other three cultivars. Seed tannins and the contribution of seeds to the total phenolic content were significantly higher in Merlot grape samples than in Pinotage, Shiraz and Cabernet Sauvignon. This can also be seen in Fig. 1. The contribution of seeds to the total phenolic content findings were similar to those of Gonzáles-Neves et al., (2004) for Merlot and Cabernet Sauvignon, but lower than those found by Cagnasso et al., (2008), who worked on Barbera, Dolcetto and Nebbiolo. High values of seed tannins could be undesired in certain red wines, as these tannins could cause increases in astringency. They also tend to associate with proteins and polysaccharides instead of stabilizing anthocyanins (Gonzáles-Neves et al., 2004). RomeroCascales et al. (2005) and Gonzáles-Neves et al. (2004) also found significantly higher values for this index in Merlot than in Cabernet Sauvignon and Shiraz, which correlated with the findings of this study.

From Fig. 1 it can also be seen that A1G, SkTG, A3.2G and AI correlated closely. Skin tannins and anthocyanins are extracted under similar conditions, leading to extracts with high levels of both these compounds (Ribereau-Gayon et al., 2006). Certain grape samples, such as C6, P1 and M1 had higher levels of A1G, SkTG, A3.2G and AI, with the latter sample having lower levels of SeTG and $\mathrm{Mp} \% \mathrm{G}$. However, no clear separation between the cultivars could be observed, which is probably due to the diversity in the origins of the different cultivars, with many factors including terrior, viticultural treatments and ripeness level affecting the phenolic composition of grapes (De Beer et al., 2006; Fournand et al., 2006; Ristic et al., 2007).

\section{Correlations between Glories, Iland and BSA methods in grapes}

The Glories and Iland extraction methods are often used in South Africa to assess the phenolic composition of red grapes during ripening and harvest time. This study correlated these two methods with each other and with the BSA method on phenolic composition of grape extracts. The correlations coefficient between the different phenolic characteristics measured with these methods are presented in Table 3. TPIG had weak, but significant correlations with Tanng, AI and TPI, whereas the same was true for the correlation of TPI with Tanng. TPIG basically measures all phenolics at $280 \mathrm{~nm}$, the same wavelength at which TPI is also measured. Condensed tannins precipitated by BSA (Tanng) would thus also contribute to total phenolics, but does not measure anthocyanins, which also contribute to the absorption values at $280 \mathrm{~nm}$. The low correlation between TPIG and TPI could be due to different extraction times and the fact that the Iland method extracts more phenolics by employing ethanol compared to the Glories method, which extracts only more

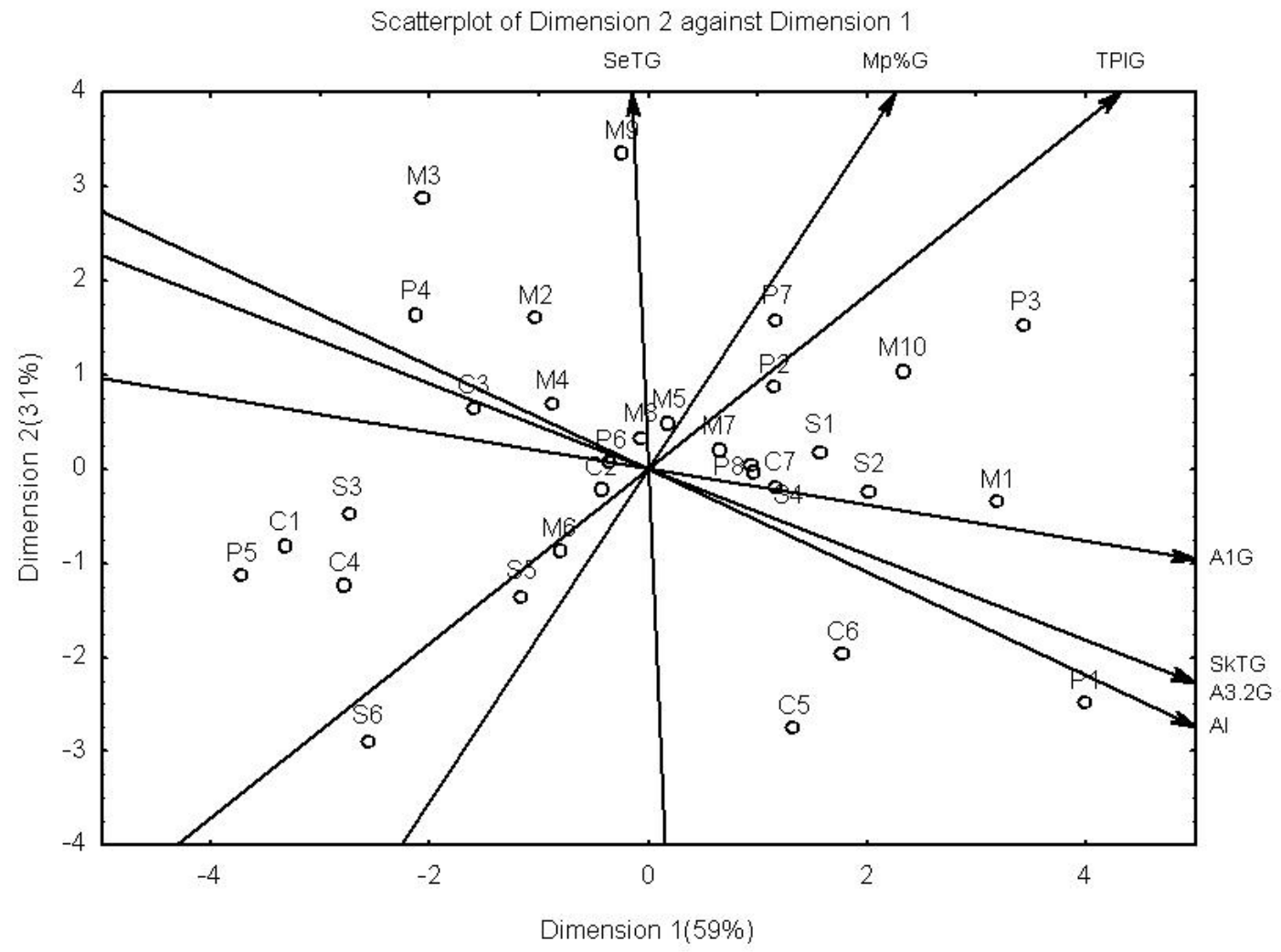

FIGURE 1

Biplot of grape phenolic data obtained from different cultivars. M: Merlot, S: Shiraz, P: Pinotage, C: Cabernet Sauvignon. 
TABLE 2

Cultivars and characteristics of the grapes used in this study.

\begin{tabular}{lllll}
\hline Cultivar & Cabernet Sauvignon & Merlot & Pinotage & Shiraz \\
\hline Soluble solids ( ${ }^{\circ}$ Balling) & $24.1 \pm 1.1^{\mathrm{b}}$ & $24.7 \pm 1.8^{\mathrm{ab}}$ & $26.1 \pm 1.6^{\mathrm{a}}$ & $25.3 \pm 1.3^{\mathrm{ab}}$ \\
pH & $3.55 \pm 0.20^{\mathrm{ab}}$ & $3.53 \pm 0.25^{\mathrm{ab}}$ & $3.44 \pm 0.17^{\mathrm{b}}$ & $3.72 \pm 0.22^{\mathrm{a}}$ \\
Total acidity (g/L) & $7.10 \pm 0.90^{\mathrm{a}}$ & $4.85 \pm 0.89^{\mathrm{b}}$ & $6.16 \pm 0.73^{\mathrm{a}}$ & $4.91 \pm 0.60^{\mathrm{b}}$ \\
TPIG (AU/L) & $47.37 \pm 7.24^{\mathrm{a}}$ & $55.40 \pm 6.89^{\mathrm{a}}$ & $54.75 \pm 10.86^{\mathrm{a}}$ & $47.23 \pm 11.64^{\mathrm{a}}$ \\
EAG & $0.77 \pm 0.12^{\mathrm{a}}$ & $0.56 \pm 0.13^{\mathrm{b}}$ & $0.570 .04^{\mathrm{b}}$ & $0.60 \pm 0.09^{\mathrm{b}}$ \\
A1G (mg/L) & $1052.25 \pm 455.37^{\mathrm{a}}$ & $1292.73 \pm 293.13^{\mathrm{a}}$ & $1405.47 \pm 553.34^{\mathrm{a}}$ & $1211.29 \pm 396.32^{\mathrm{a}}$ \\
A3.2G (mg/L) & $768.00 \pm 222.70^{\mathrm{a}}$ & $709.80 \pm 216.86^{\mathrm{a}}$ & $780.72 \pm 278.30^{\mathrm{a}}$ & $713.71 \pm 198.80^{\mathrm{a}}$ \\
SkTG & $29.95 \pm 8.70^{\mathrm{a}}$ & $27.68 \pm 8.46^{\mathrm{a}}$ & $30.45 \pm 10.85^{\mathrm{a}}$ & $27.83 \pm 7.75^{\mathrm{a}}$ \\
SeTG & $16.65 \pm 6.52^{\mathrm{b}}$ & $27.01 \pm 7.60^{\mathrm{a}}$ & $23.52 \pm 8.49^{\mathrm{ab}}$ & $18.69 \pm 5.43^{\mathrm{b}}$ \\
Mp\%G & $0.16 \pm 0.035^{\mathrm{b}}$ & $0.22 \pm 0.033^{\mathrm{a}}$ & $0.21 \pm 0.052^{\mathrm{ab}}$ & $0.17 \pm 0.059^{\mathrm{b}}$ \\
Tanng (mg/L) & $183.0235 .84^{\mathrm{a}}$ & $201.87 \pm 44.93^{\mathrm{a}}$ & $219.61 \pm 37.90^{\mathrm{a}}$ & $185.22 \pm 26.83^{\mathrm{a}}$ \\
AI (mg/g) & $1.02 \pm 0.37^{\mathrm{a}}$ & $1.04 \pm 0.26^{\mathrm{a}}$ & $1.15 \pm 0.31^{\mathrm{a}}$ & $1.32 \pm 0.36^{\mathrm{a}}$ \\
TPI (AU/g) & $1.18 \pm 0.15^{\mathrm{a}}$ & $1.11 \pm 0.14^{\mathrm{a}}$ & $1.16 \pm 0.19^{\mathrm{a}}$ & $1.25 \pm 0.15^{\mathrm{a}}$ \\
\hline Differ & &
\end{tabular}

Different letters indicates significance at $\mathrm{p}<0.05$

TABLE 3

Correlation coefficients ( $\mathrm{r}$ ) between phenolic characteristics analysed with the Glories, Iland and BSA methods.

\begin{tabular}{ccc}
\hline $\begin{array}{c}\text { Variables: } \\
\text { Glories or BSA }\end{array}$ & BSA or Iland & $\mathrm{r}$ \\
\hline \multirow{3}{*}{ TPIG } & Tanng & $0.49^{*}$ \\
& AI & $0.46^{*}$ \\
& TPI & $0.39^{*}$ \\
SeTG & Tanng & $0.4^{*}$ \\
& AI & -0.23 \\
& TPI & -0.06 \\
Mp\%G & Tanng & $0.49^{*}$ \\
& AI & 0.21 \\
& TPI & 0.22 \\
SkTG & Tanng & 0.04 \\
& AI & $0.64^{*}$ \\
& TPI & $0.37^{*}$ \\
A3.2G & Tanng & 0.16 \\
& AI & $0.73^{*}$ \\
& TPI & $0.4^{*}$ \\
A1G & Tanng & 0.12 \\
& AI & $0.75^{*}$ \\
& TPI & $0.37^{*}$ \\
EAG\% & Tanng & 0.15 \\
& AI & -0.35 \\
Tanng & TPI & 0.06 \\
& AI & 0.22 \\
& TPI & $0.39^{*}$ \\
\hline
\end{tabular}

* indicates significance at $\mathrm{p}<0.05$ easily extractable phenolics (Fragoso et al., 2010).

SeTG and Mp\%G also showed a weak, but significant correlation with Tanng. Tanng measures tannins being precipitated by BSA, which could depend on the conformation and size of the tannin compound; whereas the SeTG are obtained by assuming that all tannins in grape extract not originating from the seeds, come from the skins. The latter is determined by the OD $280 \mathrm{~nm}$ to $\mathrm{A} 3.2 \mathrm{G}$ ratio, which has been established to be 40 for ripe grapes (Ribéreau-Gayon et al., 2006). The BSA analysis of condensed tannins was also performed on extracts to which $50 \%$ ethanol has been added (used for the Iland method as well), which increases the extraction of tannins from seeds compared to the Glories method which only employs an acidified medium. These different methods and principles of determining tannin concentrations might thus influence the correlations between these two measurements, leading to them not being very strong. However, it was also interesting to note that no significant correlation was found between SkTG and Tanng, which could be due to proteins preference to bind to seed tannins over skin tannins (Gonzáles-Neves et al., 2004).

SkTG showed a stronger, significant correlation with AI, which is due to the similar extraction of anthocyanins and skin tannins previously mentioned (Ribéreau-Gayon et al., 2006). Stronger, significant correlations of 0.73 and 0.75 between $\mathrm{A} 3.2 \mathrm{G}$ with $\mathrm{AI}$ and $\mathrm{A} 1 \mathrm{G}$ with AI respectively, were also observed (Table 3 ). These methods all measure anthocyanins in the skins, with an acid medium rupturing proteophosolipid membrane, breaking protein bonds and releasing anthocyanins from the cells vacuole in the case

TABLE 4

Average values of phenolic and colour characteristics of different wines after alcoholic fermentation produced from grape cultivars used in this study.

\begin{tabular}{|c|c|c|c|c|}
\hline Cultivar: & Cabernet Sauvignon & Merlot & Pinotage & Shiraz \\
\hline $\mathrm{TPa}(\mathrm{AU}$ at $280 \mathrm{~nm})$ & $45.74 \pm 8.50^{\mathrm{a}}$ & $45.85 \pm 11.07^{\mathrm{a}}$ & $49.49 \pm 6.57^{\mathrm{a}}$ & $52.18 \pm 4.46^{\mathrm{a}}$ \\
\hline TRPa (AU 520nm) & $29.87 \pm 6.19^{\mathrm{a}}$ & $27.88 \pm 6.92^{\mathrm{a}}$ & $31.94 \pm 5.32^{\mathrm{a}}$ & $33.84 \pm 5.22^{\mathrm{a}}$ \\
\hline $\mathrm{CDa} *$ & $14.70 \pm 4.42^{\mathrm{a}}$ & $16.21 \pm 4.68^{\mathrm{a}}$ & $13.46 \pm 4.38^{\mathrm{a}}$ & $17.03 \pm 4.76^{\mathrm{a}}$ \\
\hline $\mathrm{MCDa} *$ & $14.83 \pm 3.99^{\mathrm{a}}$ & $14.10 \pm 3.97^{\mathrm{a}}$ & $13.79 \pm 3.32^{\mathrm{a}}$ & $16.32 \pm 3.42^{\mathrm{a}}$ \\
\hline $\mathrm{Aa}(\mathrm{mg} / \mathrm{L})$ & $694.02 \pm 133.96^{\mathrm{ab}}$ & $657.48 \pm 160.87^{\mathrm{b}}$ & $784.14 \pm 134.41^{\mathrm{ab}}$ & $816.23 \pm 145.01^{\mathrm{a}}$ \\
\hline $\mathrm{CPa}(\mathrm{AU} 520 \mathrm{~nm})$ & $0.68 \pm 0.17^{\mathrm{a}}$ & $0.62 \pm 0.17^{\mathrm{a}}$ & $0.66 \pm 0.14^{\mathrm{a}}$ & $0.69 \pm 0.17^{\mathrm{a}}$ \\
\hline $\mathrm{SO} 2 \mathrm{a}(\mathrm{AU} 520 \mathrm{~nm})$ & $3.74 \pm 0.90^{\mathrm{a}}$ & $2.74 \pm 1.13^{\mathrm{b}}$ & $2.35 \pm 0.56^{\mathrm{b}}$ & $2.80 \pm 0.59^{\mathrm{ab}}$ \\
\hline Tanna $\mathrm{mg} / \mathrm{L}$ & $445.33 \pm 152.10^{\mathrm{a}}$ & $430.50 \pm 168.43^{\mathrm{a}}$ & $520.73 \pm 138.05^{\mathrm{a}}$ & $475.89 \pm 74.20^{\mathrm{a}}$ \\
\hline
\end{tabular}

* Sum of AU at 420, 520 and $620 \mathrm{~nm}$. Different letters indicates significance at $\mathrm{p}<0.05$ 
TABLE 5

Average values of phenolic and colour characteristics of different wines after malolactic fermentation produced from grape cultivars used in this study.

\begin{tabular}{lllll}
\hline Cultivar: & Cabernet Sauvignon & Merlot & Pinotage & Shiraz \\
\hline TPa (AU at 280nm) & $41.70 \pm 7.11^{\mathrm{ab}}$ & $39.69 \pm 7.38^{\mathrm{b}}$ & $47.60 \pm 4.72^{\mathrm{a}}$ & $47.81 \pm 2.90^{\mathrm{a}}$ \\
TRPa (AU 520nm) & $22.94 \pm 4.80^{\mathrm{bc}}$ & $19.39 \pm 3.04^{\mathrm{c}}$ & $27.14 \pm 4.09^{\mathrm{a}}$ & $26.26 \pm 3.94^{\mathrm{ab}}$ \\
CDa $*$ & $10.59 \pm 3.23^{\mathrm{a}}$ & $10.51 \pm 3.21^{\mathrm{a}}$ & $10.78 \pm 3.79^{\mathrm{a}}$ & $11.64 \pm 2.01^{\mathrm{a}}$ \\
MCDa $*$ & $9.73 \pm 2.17^{\mathrm{a}}$ & $9.73 \pm 2.76^{\mathrm{a}}$ & $10.84 \pm 2.85^{\mathrm{a}}$ & $11.26 \pm 2.03^{\mathrm{a}}$ \\
$\mathrm{Aa}(\mathrm{mg} / \mathrm{L})$ & $515.70 \pm 115.34^{\mathrm{bc}}$ & $436.37 \pm 55.83^{\mathrm{c}}$ & $650.35 \pm 96.76^{\mathrm{a}}$ & $605.95 \pm 100.93^{\mathrm{ab}}$ \\
CPa (AU 520nm) & $0.53 \pm 0.14^{\mathrm{ab}}$ & $0.52 \pm 0.11^{\mathrm{b}}$ & $0.68 \pm 0.18^{\mathrm{a}}$ & $0.63 \pm 0.13^{\mathrm{ab}}$ \\
SO2a (AU 520nm) & $3.29 \pm 0.71^{\mathrm{a}}$ & $3.10 \pm 1.36^{\mathrm{a}}$ & $2.88 \pm 1.17^{\mathrm{a}}$ & $3.13 \pm 0.30^{\mathrm{a}}$ \\
Tanna mg/L & $260.01 \pm 159.28^{\mathrm{a}}$ & $272.66 \pm 166.73^{\mathrm{a}}$ & $408.99 \pm 123.39^{\mathrm{a}}$ & $345.44 \pm 110.33^{\mathrm{a}}$ \\
\hline
\end{tabular}

* Sum of AU at 420,520 and $620 \mathrm{~nm}$. Different letters indicates significance at $\mathrm{p}<0.05$

of A1G (Ribéreau-Gayon et al., 2006). Ethanol in the case of the Iland method is also an efficient extraction medium, leading to a high efficiency of anthocyanin extraction (Downey et al., 2007). Fragoso et al. (2010) also found high correlations between anthocyanin concentrations obtained with the Glories and Iland methods.

\section{Colour and phenolic composition of wine}

The colour and phenolic composition of the different cultivar wines after alcoholic fermentation and malolactic fermentation respectively can be seen in Tables 4 and 5. In general values were in range of other studies that investigated the phenolic and colour composition of wines made from the same cultivars (De Beer et al., 2004; Gonzáles-Neves et al., 2004; Du Toit et al., 2006a; Ristic et al., 2007; Versari et al., 2007; Habertson et al., 2008). One way ANOVA did not indicate significant differences between the different wines just after AF, except for Aa which was significantly higher in Shiraz than in Merlot. SO2 a was also significantly higher in Cabernet Sauvignon wines than in Merlot and Pinotage (Table 4). PCA on the wine data AF did not show clear trends in terms of cultivars, with PC 1 and 2 explaining $82 \%$ of the variance. (Fig 2a). However, the loadings indicated positive correlation between TRPa, Aa, CDa, MCDa and TPa, which were negatively correlated with Tanna (Figure $2 \mathrm{~b}$ ). This is not surprising, as most of the characteristics that correlated positively, measured characteristics related to the colour of red wine.

More significant differences were observed between the cultivars after MLF. After MLF TP, TRP, A and CP in Merlot wines were significantly lower than in the wines from the other three cultivars. Gonzáles-Neves et al. (2004) and Romero-Cascales et al. (2005) found Cabernet Sauvignon and Shiraz wines to have significantly higher anthocyanin levels than Merlot wines, which also correlated with the results of this study. In general, most phenolic and colour characteristics was lower after MLF and it is known that MLF can affect the colour and phenolic characteristics of red wines (Guadalupe \& Ayestaran, 2008; Geldenhuys, 2009). PCA on the wine data MLF also indicated trends in cultivar separation, with PC 1 and 2 explaining $83 \%$ of the variance (Figure 3a). Most Merlot wines were correlated with Tannb, while one Merlot wine, M1, again correlated with higher colour measurements, such as $\mathrm{MCDb}, \mathrm{CDb}$ and $\mathrm{CPb}$ (Figure 3b). M1 grapes displayed higher colour characteristics when compared to the other Merlot samples, which were followed through during AF and MLF. This study did not observe such a clear separation for the other cultivar wines.

\section{Correlations between grape and wine phenolic characteristics}

In Table 6 the correlations coefficients (r) between grape (Glories, Iland and BSA methods) and wine characteristics

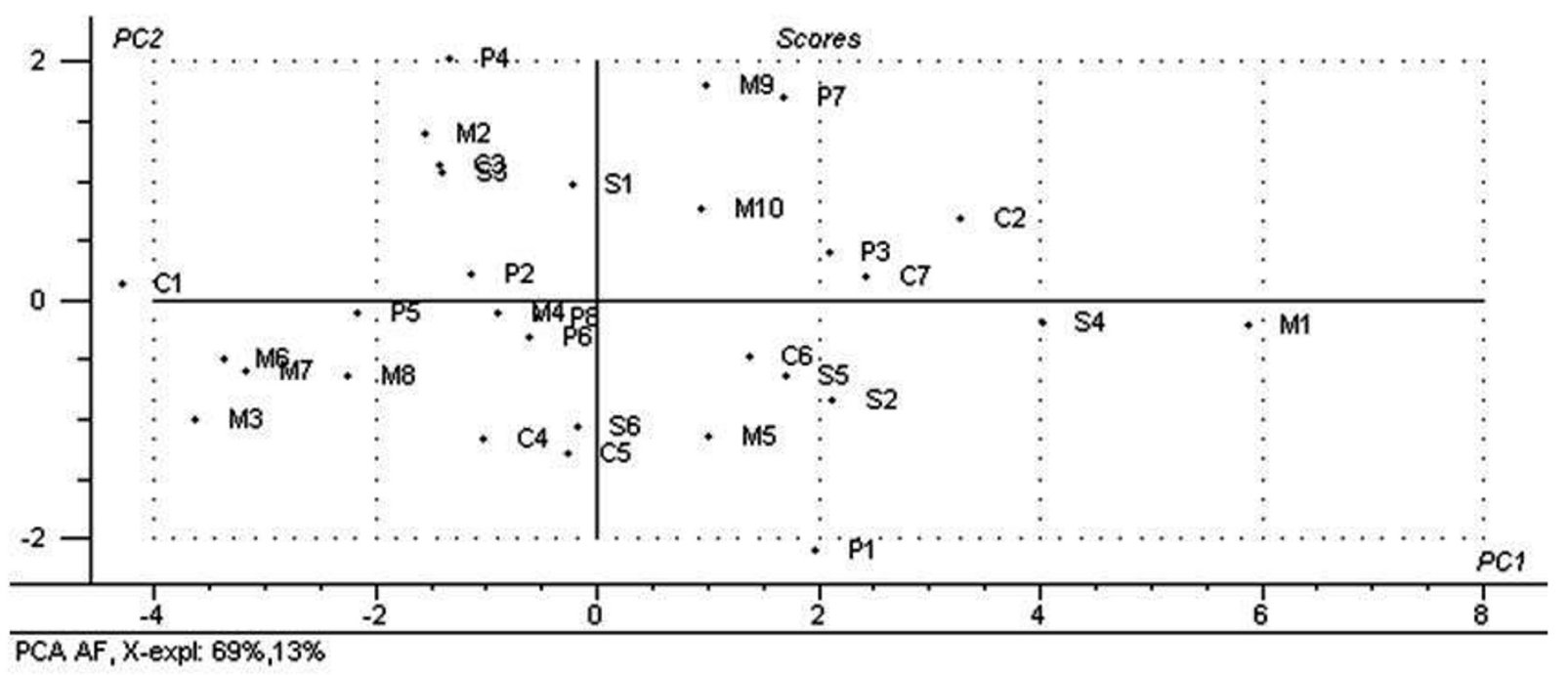

FIGURE 2a

PCA plot of wine samples after alcoholic fermentation. M: Merlot, S: Shiraz, P: Pinotage, C: Cabernet Sauvignon. 
can be seen. Strong, positive correlations were observed between $\mathrm{AI}$ and $\mathrm{CDa}, \mathrm{MCDa}$ and MCDb. A1G and A3.2G were also significantly correlated with these wine parameters, but to a slightly lower extent. TRP, A and $\mathrm{CP}$ which basically measures red pigments at a low $\mathrm{pH}$, free anthocyanins and co-pigmentation in wine, were also better correlated with AI than A1G and A3.2G. This could be due to the fact that the Iland measurements were performed from extracts obtained with an ethanol extraction, which could simulate an alcoholic fermentation better than an acidified based extract as is the case with the Glories measurements. $\mathrm{CDa}, \mathrm{CDb}, \mathrm{MCDa}$, $\mathrm{MCDb}$ also showed significant correlations with TPI, TPIG and SkTG. TPI and TPIG measures all phenolic compounds, including anthocyanins, which are primarily responsible for colour characteristics in red wine.

The EA, being an indication of the extraction of anthocyanins by taking into account the total anthocyanins (A1G) and anthocyanin extractable under winemaking conditions (A3.2G), should thus correlate with anthocyanin and colour levels in the wine. Interesting enough this study did not find any significant correlation between EA and most colour characteristics of the wine. This could be due to the fact that all the grape samples were harvested during commercial harvest and had relative high sugar levels, which led to a high level of extractability in all the grape samples, irrespective of the total anthocyanins available in the grapes. According to Roedinger (2011) an EA value of around 0.6 or higher is considered a good level for extraction. EA thus seems to fulfill a secondary role in anthocyanin extraction and it is thus debatable how effective the EA index is in predicting total extractability of anthocyanins from ripe grapes. However, it may still provide information on how quickly anthocyanins may extracted during skin contact of wine fermentations (Cagnasso et al., 2008).

Correlation between $\mathrm{SO} 2$ resistant pigments after MLF (SO2 b) with AI, A1G and A3.2G was much better than with those same wines just after AF (SO2 a). This measurement gives an idea of polymerisation of anthocyanins. Anthocyanins involved in polymerisation reactions are less prone to $\mathrm{SO}_{2}$ bleaching and colour changes due to $\mathrm{pH}$ changes. The bisulfite

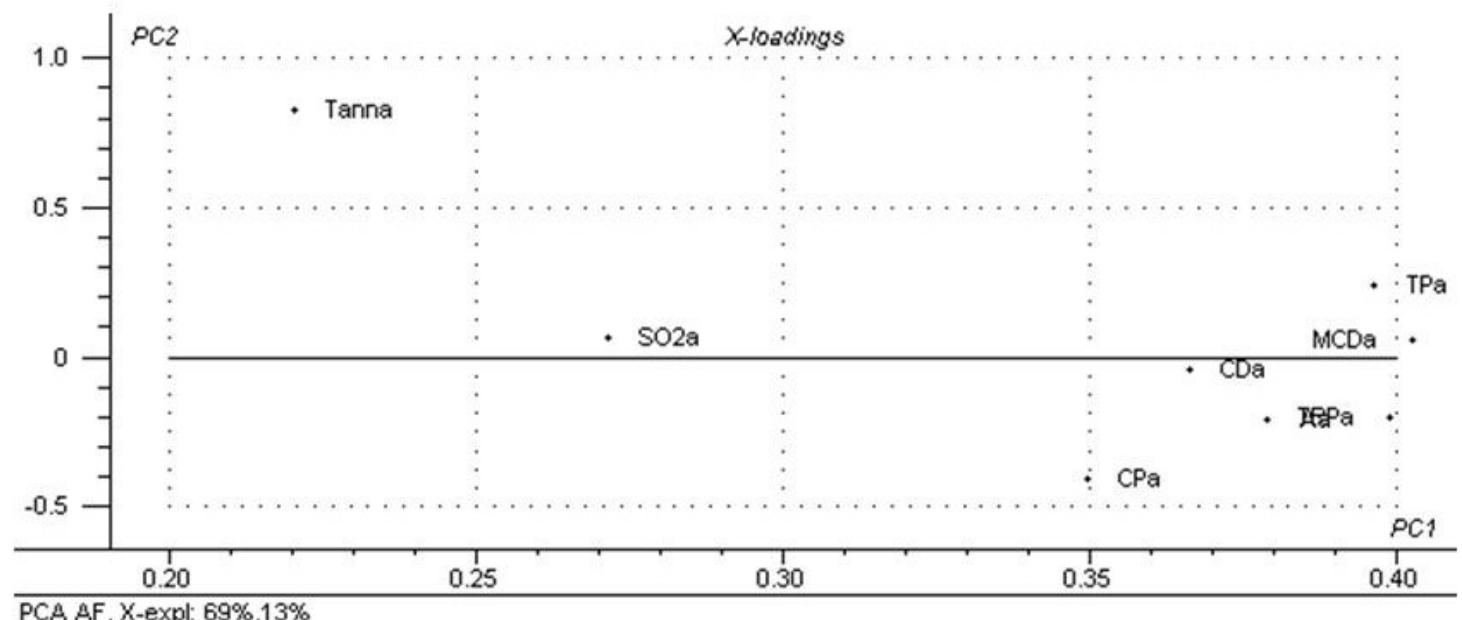

FIGURE $2 b$

Score plot of wine samples after alcoholic fermentation. M: Merlot, S: Shiraz, P: Pinotage, C: Cabernet Sauvignon.

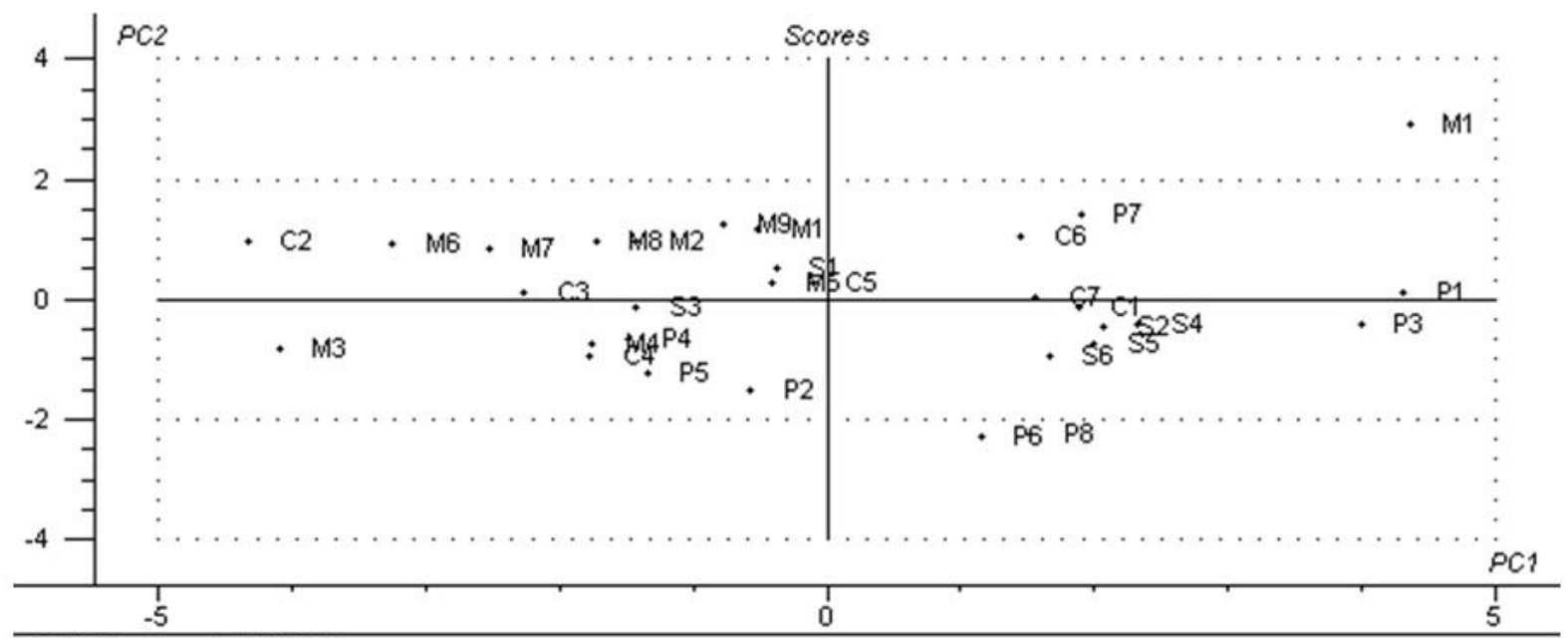

RESULT8, X-expl: $67 \%, 16 \%$

FIGURE 3a

PCA plot of wine samples after malolactic fermentation. M: Merlot, S: Shiraz, P: Pinotage, C: Cabernet Sauvignon. 


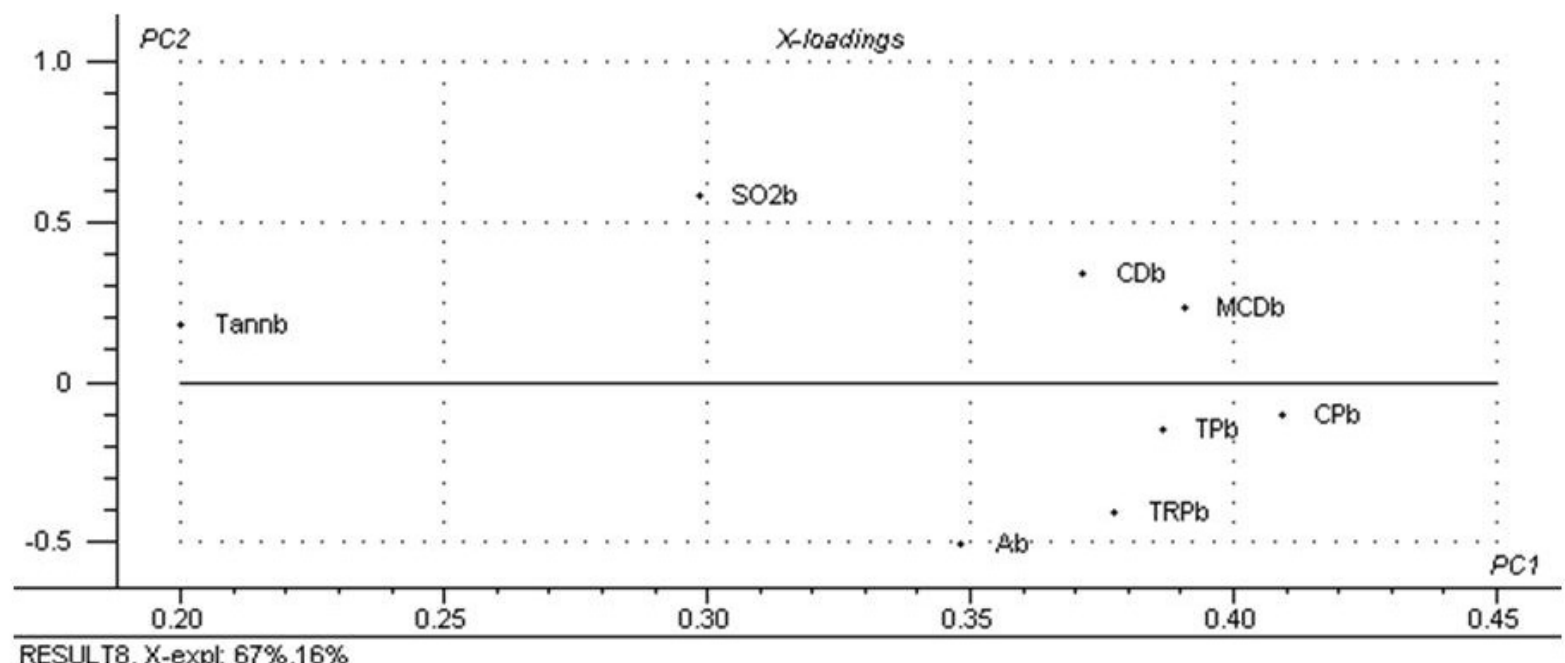

FIGURE $3 b$

Score plot of wine samples after malolactic fermentation. M: Merlot, S: Shiraz, P: Pinotage, C: Cabernet Sauvignon.

TABLE 6

Correlation coefficients ( $\mathrm{r}$ ) between grape and wine colour and phenolic characteristics $(\mathrm{n}=31)$.

\begin{tabular}{lcccccccccc}
\hline Wine characteristics: & \multicolumn{2}{l}{ Grape characteristics: } & & & & & \\
& AI & A1G & A3.2G & EA & TPI & TPIG & SkTG & SeTG & Mp\% & Tanng \\
\hline $\mathrm{CDa}$ & $0.76^{*}$ & $0.63^{*}$ & $0.66^{*}$ & -0.09 & $0.62^{*}$ & $0.57^{*}$ & $0.62^{*}$ & -0.1 & $0.40^{*}$ & 0.36 \\
$\mathrm{CDb}$ & $0.59^{*}$ & $0.56^{*}$ & $0.62^{*}$ & -0.01 & $0.46^{*}$ & $0.47^{*}$ & $0.62^{*}$ & -0.32 & 0.21 & 0.15 \\
$\mathrm{MCDa}$ & $0.66^{*}$ & $0.51^{*}$ & $0.59^{*}$ & 0.15 & $0.70^{*}$ & $0.50^{*}$ & $0.57^{*}$ & -0.14 & $0.35^{*}$ & 0.38 \\
$\mathrm{MCDb}$ & $0.72^{*}$ & $0.57^{*}$ & $0.62^{*}$ & -0.10 & $0.55^{*}$ & $0.41^{*}$ & $0.62^{*}$ & $-0.38^{*}$ & 0.12 & 0.18 \\
$\mathrm{TRPa}$ & $0.80^{*}$ & $0.64^{*}$ & $0.66^{*}$ & -0.04 & $0.70^{*}$ & $0.44^{*}$ & $0.63^{*}$ & -0.31 & 0.21 & 0.25 \\
$\mathrm{TRPb}$ & $0.47^{*}$ & 0.35 & $0.41^{*}$ & -0.03 & 0.31 & 0.15 & $0.42^{*}$ & $-0.45^{*}$ & -0.08 & -0.04 \\
$\mathrm{Aa}$ & $0.79^{*}$ & $0.51^{*}$ & $0.60^{*}$ & -0.10 & $0.63^{*}$ & 0.37 & $0.60^{*}$ & -0.21 & 0.14 & 0.25 \\
$\mathrm{Ab}$ & $0.44^{*}$ & 0.34 & $0.38^{*}$ & -0.09 & 0.28 & 0.16 & $0.39^{*}$ & $-0.41^{*}$ & -0.05 & -0.07 \\
$\mathrm{CPa}$ & $0.65^{*}$ & $0.42^{*}$ & $0.53^{*}$ & -0.04 & $0.47^{*}$ & 0.25 & $0.53^{*}$ & -0.29 & 0.03 & 0.14 \\
$\mathrm{CPb}$ & $0.61^{*}$ & $0.56^{*}$ & $0.58^{*}$ & -0.14 & $0.41^{*}$ & $0.42^{*}$ & $0.59^{*}$ & -0.31 & 0.19 & 0.10 \\
$\mathrm{SO} 2 \mathrm{a}$ & $0.18^{*}$ & -0.10 & 0.18 & $0.48^{*}$ & $0.44^{*}$ & 0.07 & 0.18 & -0.23 & -0.06 & 0.19 \\
$\mathrm{SO} \mathrm{b}$ & $0.53^{*}$ & $0.43^{*}$ & $0.54^{*}$ & 0.09 & $0.51^{*}$ & $0.36^{*}$ & $0.54^{*}$ & -0.26 & 0.11 & 0.19 \\
$\mathrm{Tanna}$ & 0.03 & -0.03 & 0.06 & 0.3 & 0.24 & 0.4 & 0.17 & $0.49 *$ & $0.45^{*}$ & $0.67^{*}$ \\
$\mathrm{Tannb}$ & 0.00 & -0.01 & 0.12 & 0.19 & 0.10 & $0.48^{*}$ & 0.14 & $0.39^{*}$ & $0.45^{*}$ & $0.54^{*}$ \\
$\mathrm{TPa}$ & $0.49^{*}$ & $0.39^{*}$ & 0.07 & 0.07 & $0.67^{*}$ & $0.52^{*}$ & $0.45^{*}$ & 0.14 & $0.41^{*}$ & $0.51^{*}$ \\
$\mathrm{TPb}$ & $0.47^{*}$ & 0.16 & 0.12 & 0.12 & 0.35 & 0.26 & 0.26 & -0.10 & 0.13 & 0.19 \\
\hline
\end{tabular}

a indicates wine samples taken after alcoholic fermentation and b wine samples taken after malolactic fermentation.

* indicates significance at $\mathrm{p}<0.05$

ion, which decolourises the anthocyanin flavilium molecule, cannot associate that easily with the polymerisation product due to steric hindrance. During MLF more anthocyanins are incorporated into a polymeric pigmented form, which is normally present at very low concentrations in grapes ( Du Toit et al., 2006a; Geldenhuys, 2009). This could explain the increased correlation of SO2 b with anthocyanin levels in the grapes, but needs further investigation, as normally very little such pigments exists in grapes.

SeTG showed positive correlations with Tanna and Tannb, due to the seeds' large contribution to the tannin composition of red wines (Busse-Valverde et al., 2011). However, it was negatively correlated with most colour characteristics, which is due to the seeds becoming riper, leading to a decrease in seed tannin's contribution to wine as anthocyanins accumulate during ripening (RibéreauGayon et al., 2006; Cagnosso et al., 2008). Tanna and Tannb correlated significantly with Tanng and the correlation coefficient value was basically the same than those found by Jensen et al. (2008) for a similar comparison between grapes and wines. TPa correlated significantly with TPI, TPIG, SkTG and Mp\%, but MLF negated these significant correlations.

The question thus arises which of the Glories or Iland methods are better to measure and predict the phenolics and colour indicative compounds in grapes that will be present in the resulting wines in a commercial cellar where expensive equipment such as HPLC is not always available. According to our findings the Iland method yielded slightly better correlations with most of the resulting wine data. However, the Glories method yields additional information, such as skin tannins and the contribution of seed tannins to the total phenolic profile of the wine. Other aspects such as chemicals required, waste generated and time should also be kept in mind when one of these two methods are considered. 


\section{CONCLUSIONS}

This study represents the first time in South Africa where these types of method comparisons were made, including for Pinotage, which was bred in South Africa. This study has shown that the $\mathrm{pH}$ of the Glories wine simulated extraction media does not have to be adjusted to South African $\mathrm{pH}$ conditions. Although no clear cut differences in terms of the phenolic and colour compositions of the cultivars have been observed, Merlot grape samples had higher levels of seed tannins according to the Glories methods and this was also reflected to some degree in the resulting wines, where Merlot wines associated more with tannins according to PCA. This should be kept in mind by wine producers, as certain seed tannins may yield harsh, astringent red wines. The BSA tannin analysis method showed potential to assess grape tannin levels and how they are reflected in the wine. Both the Glories and Iland methods showed significant positive correlation between grape and wine phenolic characteristics, although this work is preliminary and further research needs to be conducted. This study showed that correlations between grapes and wines needs to be assessed not only after AF, but should take MLF and, in future, ageing of wine in barrel into account. Future work should also compare these methods with more advanced analytical techniques such as HPLC to assess correlation between grapes and wines. Other future research could focus on a specific region and also take the variability of vintages into account.

\section{LITERATURE CITED}

Boulton, R., 2001. The copigmentation of anthocyanins and its role in the color of red wine: a critical review. Am. J. Enol. Vitic. 52, 67-87.

Busse-Valverde, N., Gomez-Plaza, E., Lopez-Roca, J.M., Gil-Munoz, R. \& Bautista-Ortín, A.B., 2011. The Extraction of Anthocyanins and Proanthocyanidins from Grapes to Wine during Fermentative Maceration Is Affected by the Enological Technique. J. Agric. Food Chem. 59, 5450 5455 .

Cagnasso, E., Rolle, L., Caudana, A. \& Gerbi, V., 2008. Relationship between grape phenolic maturity and red wine phenolic composition. Ital. J. Food Sci. 20, 365-380.

Celotti, E. \& Carcereri De Prati, G., 2005. The phenolic quality of red grapes at delivery: objective evaluation with colour measurements. S. Afr. J. Enol. Vitic. 26, 75-80.

De Beer, D., Habertson, J.F., Kilmartin, P.A., Roginsky, V., Barsukova, T., Adams, D.O. \& Waterhouse, A.L., 2004. Phenolics : a comparison of diverse analytical methods. Am. J. Enol. Vitic. 55, 389-399.

De Beer, D., Joubert, E., Marais, J., Manley, M. \& Van Schalkwyk, D., 2006. Climatic region and vine structure: effect on Pinotage wine phenolic composition, total antioxidant capacity and colour. S. Afr. J. Enol. Vitic. 27, 151-166.

De Freitas, V.A.P., Glories, Y. \& Monique, A., 2000. Development changes of procyanidins in grapes of red Vitis vinifera varieties and their composition in respective wines. Am. J. Enol. Vitic. 51, 397-403.

Downey, M.O., Mazza, M. \& Krstic, M.P., 2007. Development of a stable extract for anthocyanins and flavonols from grape skin. Am. J. Enol. Vitic. $58,358-364$

Du Toit, W.J., Marais, J., Pretorius I.S. \& Du Toit, M., 2006a. Oxygen in must and wine: A review. S. Afr. J. Enol. Vitic. 27, 76-94.
Du Toit, W.J., Lisjak, K., Marais, J. \& Du Toit, M., 2006b. The effect of micro-oxygenation on the phenolic composition, quality and aerobic winespoilage microorganisms of different South African red wines. S. Afr. J. Enol. Vitic. 27, 57-67.

Geldenhuys, L., 2009. Influence of oxygen addition on the phenolic composition of red wine. MScAgric thesis - Oenology, Stellenbosch University, 2009. 110 pp.

Fragoso, S., Mestres, M., Busto, O. \& Guasch, J., 2010. Comparison of three extraction methods used to evaluate phenolic ripening in red grapes. J. Agric. Food Chem. 58, 4071-4076.

Fournand, D., Vicens, A., Sidhoum, L., Souquet, J.M., Moutounet, M. \& Chenynier, V., 2006. Accumulation and extractability of grape skin tannins and anthocyanins at different advanced physiological stages. J. Agric. Food Chem. 54, 7331-7338.

Guadalupe, Z. \& Ayestaran, B., 2008., Changes in the color components and phenolic content of red wines from Vitis vinifera L. Cv. "Tempranillo" during vinification and aging. Eur. Food Res. Technol. 228, 29-39.

González-Neves, G., Charamelo, D., Balado, J., Barreiro, L., Bochiccio, R., Gatto, G., Gil, G., Tessore, A., Carbonneau, A. \& Moutounet, M., 2004. Phenolic potential of Tannat, Cabernet Sauvignon and Merlot grapes and their correspondence with wine composition. Anal. Chim. Acta. 513, 191196.

Habertson, J.F., Hodgins, R.E., Thurston, L.N., Schaffer, L.J., Reid, M.S Landon, J.L., Ross, C.F. \& Adams, D.O., 2008. Research note: Variability of tannin concentration in red wines. Am. J. Enol. Vitic. 59, 210-214.

Iland, P., 2004. Chemical analysis of grapes and wine: techniques and concepts; Patrick Iland Wine promotions: Campbelltown, Australia. p.110.

Jensen, J.S., Demiray, S., Egebo, M. \& Meyer, A.S., 2008. Prediction of wine color attributes from the phenolic profiles of red grapes (Vitis vinifera). J. Agric. Food Chem.. 56, 1105-1115.

Marais, J. \& October, F., (2005). Relationship between grape colour and wine quality. http://wynboer.co.za/recentarticles/200507colour.php3

Nieuwoudt, H.H., Prior, B.A., Pretorius, I.S., Manley, M. \& Bauer, F.F., 2004. Principal component analysis applied to Fourier transform infrared spectroscopy for the design of calibration sets for glycerol prediction models in wine and for the detection and classification of outlier samples. J. Agric. Food Chem. 52, 3728-3735.

Ribéreau-Gayon, P., Glories, Y., Maujean, A. \& Dubourdieu, D., 2006. Handbook of Enology, Volume 2: The chemistry of wine stabilization and treatments. Ed. Ribéreau-Gayon P., Wiley, Chichester, England.

Ristic, R., Downey, M.O., Iland, P.G., Bindon, K., Francis, I.L., Herderich, M. \& Robinson, S. P., 2007. Exclusion of sunlight from Shiraz grapes alters wine colour, tannin and sensory properties. Aust. J. Grape Wine Res. 16, 53-65.

Roedinger, 2011. Personnel communication

Romero-Cascales, I., Ortega-Regules, A., López-Roca, J.M., FernándezFernández J.I. \& Gómez-Plaza, E., 2005. Differences in anthocyanins extractability from grapes to wines according to variety. Am. J. Enol. Vitic. 56, 212-219.

Rossouw M. \& Marais, J., 2004. The phenolic composition of South African Pinotage, Shiraz and Cabernet Sauvignon wines. S. Afr. J. Enol. Vitic. 25, 94-104.

Versari, A., Parpinello, G.P. \& Mattioli, A.U., 2007. Characterization of colour components and polymeric pigments of commercial red wines by using selected UV-VIS spectrophotometric methods. S. Afr. J. Enol. Vitic. 28, 6-10. 